\title{
Evolution of Photoluminescence across Dimensionality in Lanthanide Silicates
}

\author{
Mariya H. Kostova, ${ }^{\dagger}$ Duarte Ananias, ${ }^{\dagger, *}$ Filipe A. Almeida Paz, ${ }^{\dagger}$ Artur Ferreira, ${ }^{\S}$ \\ João Rocha, ${ }^{*, \dagger}$ and Luís D. Carlos $*, \|$ \\ Departments of Chemistry and Physics and ESTGA, CICECO, University of Aveiro, 3810-193 Aveiro, and \\ Department of Biochemistry, University of Coimbra, 3001-401 Coimbra, Portugal
}

Received: December 13, 2006; In Final Form: February 8, 2007

\begin{abstract}
The dehydratation process of layered lanthanide silicates $\mathrm{K}_{3}\left[\mathrm{LnSi}_{3} \mathrm{O}_{8}(\mathrm{OH})_{2}\right], \mathrm{Ln}=\mathrm{Y}, \mathrm{Eu}, \mathrm{Tb}$, and $\mathrm{Er}$, and the structural characterization of the obtained small-pore framework $\mathrm{K}_{3} \mathrm{LnSi}_{3} \mathrm{O}_{9}, \mathrm{Ln}=\mathrm{Y}, \mathrm{Eu}, \mathrm{Tb}$, and $\mathrm{Er}$ solids, named AV-23, have been reported. The structure of AV-23 has been solved by single-crystal X-ray diffraction (XRD) methods and further characterized by chemical analysis, thermogravimetry, scanning electron microscopy, and ${ }^{29} \mathrm{Si}$ MAS NMR. The photoluminescence (PL), radiance, and lifetime values of AV-23 have been studied and compared with those of AV-22. Both materials have a similar chemical makeup and structures sharing analogous building blocks, hence providing a unique opportunity for rationalizing the evolution of the PL properties of lanthanide silicates across dimensionality. Although Tb-AV-23 contains a single crystallographic $\mathrm{Tb}^{3+}$ site, PL spectroscopy indicates the presence of $\mathrm{Ln}^{3+}$ centers in regular framework positions and in defect regions. PL evidence suggests that Eu-AV-23 contains a third type of $\mathrm{Ln}^{3+}$ environment, namely, $\mathrm{Eu}^{3+}$ ions replacing $\mathrm{K}^{+}$ions in the micropores. The radiance values of the Tb-AV-22 and Tb-AV-23 samples are of the same order of magnitude as those of standard $\mathrm{Tb}^{3+}$ green phosphors. For the samples $\mathrm{K}_{3}\left(\mathrm{Y}_{1-a} \mathrm{Er}_{a} \mathrm{Si}_{3} \mathrm{O}_{9}\right), a=0.005-1$, efficient emission and larger ${ }^{4} \mathrm{I}_{13 / 2}$ lifetimes (ca. $7 \mathrm{~ms}$ ) are detected for low $\mathrm{Er}^{3+}$ content, indicating that the $\mathrm{Er}^{3+}-\mathrm{Er}^{3+}$ interactions become significant as the $\mathrm{Er}^{3+}$ content increases.
\end{abstract}

\section{Introduction}

Microporous $^{1-4}$ and layered ${ }^{5}$ lanthanide silicates are hostguest systems suitable for engineering multifunctional materials with tunable properties. These solids have $\mathrm{Ln}^{3+}$ cations in the frameworks, layers, micropores, and interlayer spaces, combining the properties of layered silicates (intercalation chemistry) or zeolites (such as ion exchange and molecular sieving) and photoluminescence (PL), and may find applications in new types of sensors (ref 6 and references therein).

At present, the research on microporous frameworks hosting $\mathrm{Ln}^{3+} \mathrm{PL}$ centers is focused on four main classes of materials: ${ }^{6}$ (a) "conventional" zeolites ion-exchanged with $\mathrm{Ln}^{3+}$, (b) lanthanide-organic ligand complexes enclosed in the zeolitic pores and channels, (c) coordination polymers (organicinorganic hybrids), and (d) lanthanide silicates, containing stoichiometric amounts of framework $\mathrm{Ln}^{3+}$ ions. On the other hand, the work available on engineering photoluminescent centers into layered materials concentrates mainly on coordination polymers ${ }^{7,8}$ and three-dimensional phosphonates, consisting of inorganic layers connected by organic groups, reminiscent of pillared structures. ${ }^{9}$ In this context, the crystal chemistry of layered lanthanide silicates has been largely overlooked, although a recent study has clearly shown their potential as efficient and tunable phosphors. ${ }^{5}$

To gain further insight into the PL mechanisms, it is of interest to bridge between the fields of lanthanide silicates with

* To whom correspondence should be addressed. Fax: +351 34370084 . Phone: +351 370730. E-mail: rocha@dq.ua.pt (J.R.); lcarlos@fis.ua.pt (L.D.C.).

Department of Chemistry, CICECO, University of Aveiro.

$\doteqdot$ University of Coimbra.

$\S$ ESTGA, CICECO, University of Aveiro.

"Department of Physics, CICECO, University of Aveiro. different dimensionality, such as layered and framework microporous materials. We have previously reported on the layered PL system $\mathrm{K}_{3}\left[\mathrm{LnSi}_{3} \mathrm{O}_{8}(\mathrm{OH})_{2}\right]$, named AV-22. ${ }^{5}$ Upon calcination at $650{ }^{\circ} \mathrm{C}, \mathrm{AV}-22$ materials undergo a phase transformation to the small-pore framework system $\mathrm{K}_{3}\left[\mathrm{LnSi}_{3} \mathrm{O}_{9}\right]$, named here $\mathrm{AV}$ 23, whose structure bears some similarity to the structure of the $\mathrm{Ho}^{3+}$ silicate first reported by Ponamarev et al. ${ }^{10} \mathrm{AV}-22$ and AV-23 have similar chemical makeup and structures which share analogous building blocks, hence providing a unique opportunity for rationalizing the PL properties of two- and threedimensional materials. Here, we report on the structure of AV$23(\mathrm{Ln}=\mathrm{Tb}, \mathrm{Eu}, \mathrm{Y}, \mathrm{Er})$ materials prepared from AV-22 precursors. We propose a simple mechanism for the AV-22 to AV-23 structural transformation and compare the PL properties of these materials.

\section{Experimental Methods}

Synthesis. The syntheses of precursor layered AV-22 silicates were carried out in Teflon-lined autoclaves (volume $37 \mathrm{~cm}^{3}$, filling rate 0.62 ), under static hydrothermal conditions, in ovens preheated at $230{ }^{\circ} \mathrm{C}$. The autoclaves were removed and quenched in cold water after an appropriate time. The obtained microcrystalline powders were filtered, washed at room temperature with distilled water, and dried at $100{ }^{\circ} \mathrm{C}$.

The synthesis of Y-AV-22, Er-AV-22, Eu-AV-22, Tb-AV22, and mixed Y/Er-AV-22 materials was performed using a previously published procedure. ${ }^{5}$

Typical AV-23 Synthesis. Because TGA reveals that the thermal transition from the layered to small-pore materials occurs in the range $550-600{ }^{\circ} \mathrm{C}, \mathrm{AV}-22$ samples were calcined at $650{ }^{\circ} \mathrm{C}$ in a stream of argon for $10 \mathrm{~h}$ (after the temperature was raised at a heating rate of $5^{\circ} \mathrm{C} / \mathrm{min}$ ). 
TABLE 1: Crystal and Structure Refinement Data for $\mathrm{K}_{3}\left[\mathrm{TbSi}_{3} \mathrm{O}_{9}\right](\mathrm{Tb}-\mathrm{AV}-23)$

$\begin{array}{ll}\text { empirical formula } & \mathrm{K}_{3} \mathrm{O}_{9} \mathrm{Si}_{3} \mathrm{~Tb} \\ \text { fw } & 504.50 \\ \text { cryst syst } & \text { orthorhombic } \\ \text { space group } & P m n 2_{1} \\ a / \AA & 14.053(3) \\ b / \AA & 5.9090(12) \\ c / \AA & 12.978(3) \\ \mathrm{vo} / / \AA^{3} & 1077.7(4) \\ Z & 4 \\ D_{\mathrm{c}} /\left(\mathrm{g} \mathrm{cm}^{-3}\right) & 3.109 \\ \mu(\mathrm{Mo} \mathrm{K} \alpha) / \mathrm{mm}^{-1} & 8.081 \\ F(000) & 944 \\ \text { cryst size/mm } & 0.17 \times 0.14 \times 0.10 \\ \text { cryst type } & \text { colorless plates } \\ \theta \text { range } & 3.74-26.37 \\ \text { index ranges } & -17 \leq h \leq+16 \\ & -7 \leq k \leq+7 \\ \text { no. of reflns collected } & -16 \leq l \leq+16 \\ \text { no. of independent reflns } & 8716 \\ \text { data completeness } & 2292\left(R_{\text {int }}=0.0430\right) \\ \text { final } R \text { indices }[I>2 \sigma(I)] & \text { to } \theta=26.37^{\circ}, 99.7 \% \\ & \mathrm{R} 1=0.1099 \\ \text { final } R \text { indices (all data) } & \text { wR2 }=0.2613 \\ & \mathrm{R} 1=0.1147 \\ \left.\text { largest diff peak and hole/(e } \AA^{-3}\right) & \text { wR2 }=0.2643 \\ & 4.855 \text { and }-4.695 \\ \end{array}$

TABLE 2: Selected Bond Lengths $(\AA)$ and Angles (deg) for the $\mathrm{Tb}^{3+}$ Coordination Environment in $\mathrm{K}_{3}\left[\mathrm{TbSi}_{3} \mathrm{O}_{9}\right]$ $(\mathrm{Tb}-\mathrm{AV}-23)^{a}$

\begin{tabular}{lclr}
\hline $\mathrm{Tb}(1)-\mathrm{O}(1)$ & $2.346(14)$ & $\mathrm{Tb}(1)-\mathrm{O}(6)^{\mathrm{ii}}$ & $2.279(11)$ \\
$\mathrm{Tb}(1)-\mathrm{O}(4)^{\mathrm{i}}$ & $2.266(13)$ & $\mathrm{Tb}(1)-\mathrm{O}(8)$ & $2.263(14)$ \\
$\mathrm{Tb}(1)-\mathrm{O}(5)$ & $2.324(17)$ & $\mathrm{Tb}(1)-\mathrm{O}(9)^{\mathrm{i}}$ & $2.293(15)$ \\
$\mathrm{O}(4)^{\mathrm{i}}-\mathrm{Tb}(1)-\mathrm{O}(1)$ & $92.3(5)$ & $\mathrm{O}(8)-\mathrm{Tb}(1)-\mathrm{O}(1)$ & $82.5(6)$ \\
$\mathrm{O}(4)^{\mathrm{i}}-\mathrm{Tb}(1)-\mathrm{O}(5)$ & $96.3(6)$ & $\mathrm{O}(8)-\mathrm{Tb}(1)-\mathrm{O}(4)^{\mathrm{i}}$ & $174.8(6)$ \\
$\mathrm{O}(4)^{\mathrm{i}}-\mathrm{Tb}(1)-\mathrm{O}(6)^{\mathrm{ii}}$ & $86.8(6)$ & $\mathrm{O}(8)-\mathrm{Tb}(1)-\mathrm{O}(5)$ & $84.0(6)$ \\
$\mathrm{O}(4)^{\mathrm{i}}-\mathrm{Tb}(1)-\mathrm{O}(9)^{\mathrm{i}}$ & $91.2(5)$ & $\mathrm{O}(8)-\mathrm{Tb}(1)-\mathrm{O}(6)^{\mathrm{ii}}$ & $92.2(5)$ \\
$\mathrm{O}(5)-\mathrm{Tb}(1)-\mathrm{O}(1)$ & $86.7(6)$ & $\mathrm{O}(8)-\mathrm{Tb}(1)-\mathrm{O}(9)^{\mathrm{i}}$ & $93.9(4)$ \\
$\mathrm{O}(6)^{\mathrm{ii}}-\mathrm{Tb}(1)-\mathrm{O}(1)$ & $85.4(5)$ & $\mathrm{O}(9)^{\mathrm{i}}-\mathrm{Tb}(1)-\mathrm{O}(1)$ & $175.6(6)$ \\
$\mathrm{O}(6)^{\mathrm{ii}}-\mathrm{Tb}(1)-\mathrm{O}(5)$ & $171.6(6)$ & $\mathrm{O}(9)^{\mathrm{i}}-\mathrm{Tb}(1)-\mathrm{O}(5)$ & $95.6(5)$
\end{tabular}

$\mathrm{O}(6)^{\mathrm{ii}}-\mathrm{Tb}(1)-\mathrm{O}(9)^{\mathrm{i}} \quad 92.1(6)$

${ }^{a}$ Symmetry transformations used to generate equivalent atoms: (i) $x, 1+y, z$; (ii) $-1 / 2-x,-2-y, 1 / 2+z$.

Characterization. SEM images were recorded on a Hitachi S-4100 microscope. EDS was carried out using an EDS Römteck System with a polymeric window attached to the scanning electron microscope. Samples purity were verified by powder XRD (X'Pert MPD Philips diffractometer, $\mathrm{Cu} \mathrm{K} \alpha_{\alpha}$ $\mathrm{X}$-radiation). The ${ }^{29} \mathrm{Si}$ magic-angle spinning (MAS) NMR spectrum of Y-AV-23 was recorded at $79.49 \mathrm{MHz}$ on a (9.4 T) Bruker Avance 400 spectrometer, using $40^{\circ}$ pulses, a spinning rate of $5 \mathrm{kHz}$, and $60 \mathrm{~s}$ recycle delays. Chemical shifts are quoted in parts per million from the peak for TMS. TGA curves were measured on a Labsys TG-DTA $1600^{\circ} \mathrm{Crod}$, from TA instruments, under nitrogen, using a $10{ }^{\circ} \mathrm{C} / \mathrm{min}$ rate.

Photoluminescence measurements were recorded on a Fluorolog-3 model FL3-2T with a double-excitation spectrometer (Triax 320), fitted with a 1200 grooves $/ \mathrm{mm}$ grating blazed at $330 \mathrm{~nm}$, and a single-emission spectrometer (Triax 320), fitted with a 1200 grooves $/ \mathrm{mm}$ grating blazed at $500 \mathrm{~nm}$, coupled to an R928P photomultiplier. The excitation sources used were a $450 \mathrm{~W}$ Xe arc lamp and a pulsed $\mathrm{Xe}-\mathrm{Hg}$ lamp, for the steadystate and time-resolved measurements, respectively. The excitation spectra were corrected from 240 to $600 \mathrm{~nm}$ for the spectral distribution of the lamp intensity using a photodiode reference detector. Emission and excitation spectra were also corrected for the spectral response of the monochromators and the detector, using typical correction spectra provided by the manufacturer. The measurements at $10-14 \mathrm{~K}$ were performed using a He closed-cycle cryostat.

When different samples were compared, the spectra were measured keeping the experimental setup fixed (slit width, irradiated area, and optics geometry). In this case, the sample pellets were prepared at the same pressure. The radiance measurements and the CIE $(x, y)$ emission color coordinates were obtained using a telescope optical probe (TOP 100 DTS140-111, Instrument Systems). The excitation source was a Xe arc lamp $(150 \mathrm{~W})$ coupled to a Jobin Yvon-Spex monochromator (TRIAX 180). The width of the rectangular excitation spot was $2 \mathrm{~mm}$ and the diameter used to collect the emission intensity $0.5 \mathrm{~mm}$, ensuring that the entire sample was illuminated. The radiances of the standard green $\mathrm{Gd}_{2} \mathrm{O}_{2} \mathrm{~S}: \mathrm{Tb}$ and red $\mathrm{Y}_{2} \mathrm{O}_{2}$ :Eu phosphors (Phosphor Technology) were also measured. The experimental conditions (excitation and detection optical alignment) were kept constant to enable the quantitative comparison between the measurements. Moreover, because radiance depends on the surface density of the emitting centers, care was also taken in the sample preparation: pellets with a ca. $0.45 \mathrm{~mm}$ thickness containing the same amount and compaction degree were made. The radiance values were corrected for the spectral distribution of the lamp intensity. The experimental error is within $5 \%$.

Raman emission spectra were recorded on an FT-Raman Bruker spectrometer, model RSF 100, at room temperature. The excitation source was a YAG:Nd laser $\left(\lambda_{\mathrm{exc}}=1064 \mathrm{~nm}\right)$ (excitation power $50 \mathrm{~mW}$ ). The energy values from the Raman shift $\left(\mathrm{cm}^{-1}\right), E_{\mathrm{R}}$, were converted into emission energy $\left(\mathrm{cm}^{-1}\right)$, $E_{\mathrm{E}}$, using the expression $E_{\mathrm{E}}=E_{\text {laser }}-E_{\mathrm{R}}$, where $E_{\text {laser }}=9398.5$ $\mathrm{cm}^{-1}$.

Single-Crystal X-ray Diffraction Studies. Several $\mathrm{K}_{3}\left[\mathrm{TbSi}_{3} \mathrm{O}_{9}\right]$ (Tb-AV-23) single crystals (from different batches), all exhibiting a poorly defined morphology, were mounted on a glass fiber using perfluoropolyether oil, ${ }^{11}$ and data were collected at 100(2) K (Unidade de Raios-X, RIAIDT, University of Santiago de Compostela, Spain) on a Bruker SMART 1000 chargecoupled device (CCD) area-detector diffractrometer equipped with Mo $\mathrm{K} \alpha$ graphite-monochromated radiation $(\lambda=0.7107$ $\AA$ ) and controlled by the SMART software package. ${ }^{12}$ Images were processed using the SAINTPlus software package, ${ }^{13}$ and data were corrected for absorption by using the semiempirical method of SADABS. ${ }^{14}$ A considerable internal disorder of all crystals was immediately indicated by the overall poor diffraction and very high mosaicities (typically around $5^{\circ}$ per reflection). Even so, a possible crystal solution for this material was attempted by solving the reduced data with SHELXS-97 ${ }^{15}$ and refining the model by full-matrix least squares on $F^{2}$ using SHELXL-97. ${ }^{16}$

The XPREP interface was used to analyze the data symmetry, with the systematic absences suggesting two possible space groups for the crystal data, $P m n 2_{1}$ and Pmmn, both characterized by relatively low figures of merit. Considering the experimental problems in the data collection and reduction, the structure was solved and refined in both space groups. Even though the calculated mean $\left|E^{2}-1\right|$ value strongly indicated a centrosymmetric Pmmn space group, this did not lead to the most sensible crystal model. The final selection of the $P m n 2_{1}$ space group was also motivated by the previous work of Ponomarev et al. reporting on a similar material, containing $\mathrm{Ho}^{3+} .10$

The location of $\mathrm{Tb}^{3+}$ was straightforward from Patterson synthesis, with the remaining atoms being located from difference Fourier maps calculated from successive least-squares 

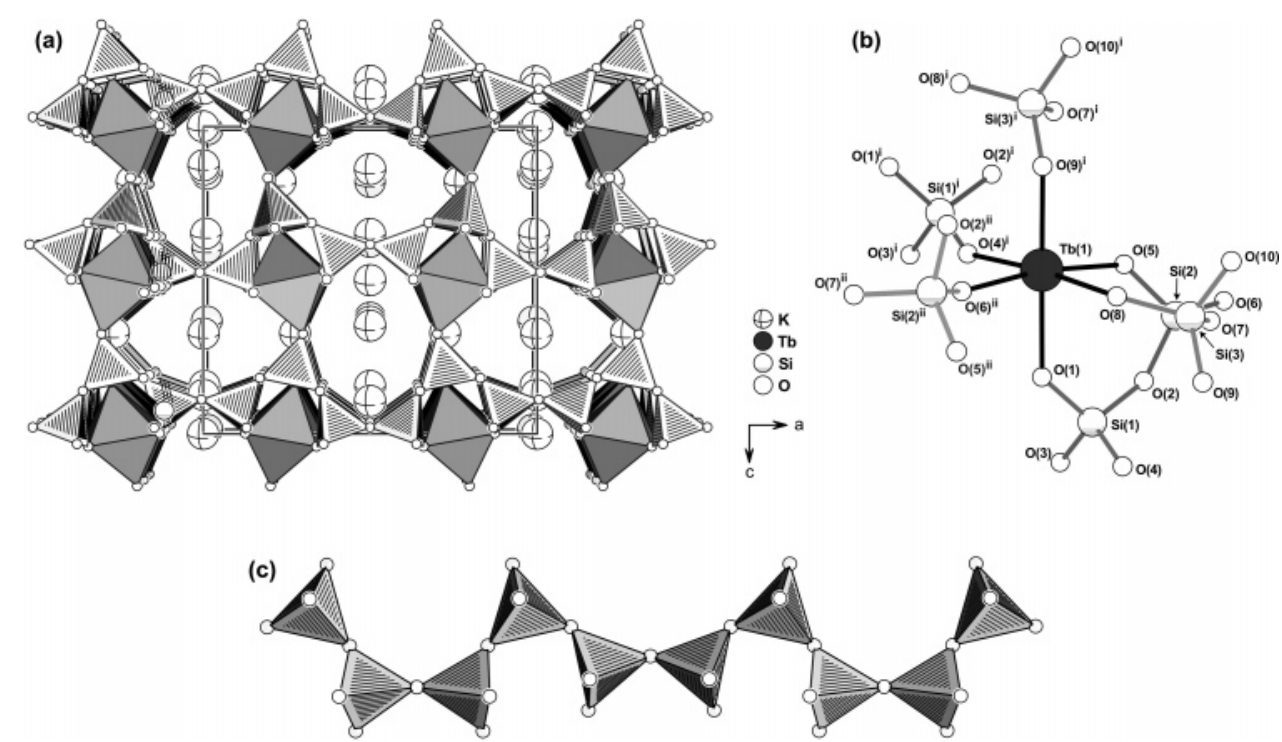

Figure 1. (a) Polyhedral representation of the crystal packing in $\mathrm{AV}-23, \mathrm{~K}_{3}\left[\mathrm{MSi}_{3} \mathrm{O}_{9}\right]\left(\mathrm{M}^{3+}=\mathrm{Tb}^{3+}\right.$ and $\left.\mathrm{Y}^{3+}\right)$, viewed along the [010] direction of the unit cell. (b) Distorted octahedral $\left\{\mathrm{TbO}_{6}\right\}$ coordination environment. Symmetry codes used to generate equivalent atoms: (i) $x, 1+y, z$; (ii) $-1 / 2-x,-2-y, 1 / 2+z$. (c) $\left(\mathrm{Si}_{6} \mathrm{O}_{17}\right)_{n}{ }^{10 n-}$ wollastonite-type silicate chain, running along [100], formed by the parallel condensation of triple siliceous tetrahedral units belonging to adjacent anionic $\left[\mathrm{MSi}_{3} \mathrm{O}_{8}(\mathrm{OH})_{2}\right]_{n}{ }^{3 n-}$ layers.

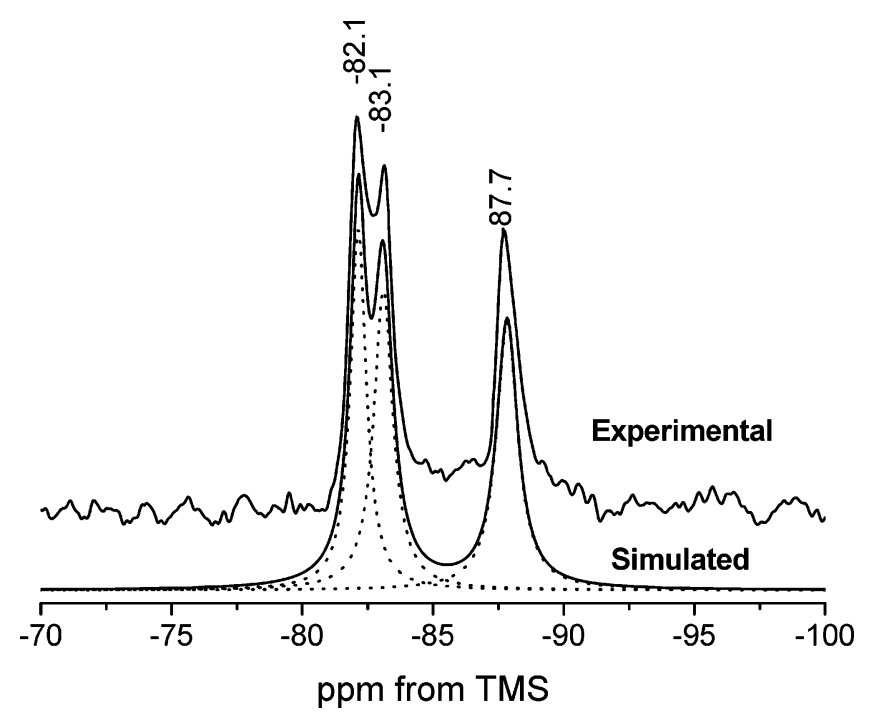

Figure 2. ${ }^{29} \mathrm{Si}$ MAS NMR spectra of Y-AV-23.

refinement cycles. The structure was refined with a geometry heavily restrained for the $\left\{\mathrm{SiO}_{4}\right\}$ tetrahedra, with all the $\mathrm{Si}-\mathrm{O}$ bond lengths and tetrahedral internal $\mathrm{O} \cdots \mathrm{O}$ distances restrained to common values, which converged to $1.60(2)$ and 2.61(2) $\AA$, respectively. The refined anionic $\left[\mathrm{TbSi}_{3} \mathrm{O}_{9}\right]_{n}{ }^{3 n-}$ small-pore framework showed the presence of several $\mathrm{Q}$ peaks inside the tunnels, assigned to highly disordered charge-balancing $\mathrm{K}^{+}$ cations. Ten crystallographic distinct $\mathrm{K}^{+}$sites were refined with variable occupancy, adding up to a fixed charge of +3 . The quality of the crystal data was not suitable for anisotropic refinement of each atom, and common refinable isotropic displacement parameters were used instead (one per atom type). To allow a sensible (and more stable) refinement of the structure, the $\mathrm{Tb}^{3+}$ center was refined using anisotropic displacement parameters to better account for the electron density around its crystallographic position. However, the atom refined as a nonpositive definite, as a consequence of the low quality of the crystal data. Toward the end of the refinement, racemic twinning of the crystals was taken into consideration and the TWIN law $(-100,0-10,00-1)$ was implemented along with one BASF parameter which refined to ca. 0.50. The last difference
Fourier map synthesis showed a residual electron density with

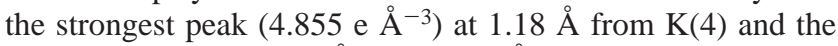

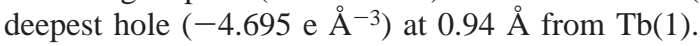

Information concerning crystallographic data collection and structure refinement details for Tb-AV-23 are summarized in Table 1. Selected bond lengths and angles are given in Table 2. Further information may be obtained free of charge from Fachinformationszentrum Karlsruhe, 76344 Eggenstein-Leopoldshafen, Germany (e-mail crysdata@fiz-karlsruhe.de), on quoting the depository number CSD-416025.

Crystals of Tb-AV-23 which were placed in an atmosphere saturated with water were also studied. The very high mosaicity of these samples (ca. $10^{\circ}$ per reflection) precluded the solution and refinement of a valid structural model. However, it was possible to successfully index the material $[a=14.203(3) \AA, b$ $=5.8910(12) \AA, c=13.089(3) \AA$, volume 1095.2(4) $\left.\AA^{3}\right]$ in space group $P m n 2_{1}\left(R_{\text {int }}=0.0580\right)$.

Y-AV-23 samples also exhibited poor crystal morphology and a very high mosaicity. A poorly diffracting crystal of Y-AV23 , saturated with water (plate prismatic $0.12 \times 0.07 \times 0.03$ mm crystal), was mounted on a Bruker KAPPA CCD-2000 CCD area-detector diffractrometer (Unidade de Raios-X, RIAIDT, University of Santiago de Compostela, Spain), equipped with $\mathrm{Cu} \mathrm{K} \alpha$ radiation $(\lambda=1.54180 \AA)$ from a rotating anode source (operated at $100 \mathrm{~mA}$ and $45 \mathrm{kV}$ ). Although the crystal diffracted only until ca. $1.2 \AA$, a primitive (P) unit cell could be determined: $a=5.889 \AA, b=13.053 \AA, c=14.163 \AA$, $\alpha$ $=\beta=\gamma=90^{\circ}$.

\section{Results and Discussion}

Crystal Structure of Tb- and Y-AV-23. The calcination of layered $\mathrm{K}_{3}\left[\mathrm{MSi}_{3} \mathrm{O}_{8}(\mathrm{OH})_{2}\right]\left(\mathrm{M}^{3+}=\mathrm{Tb}^{3+}\right.$ and $\left.\mathrm{Y}^{3+}\right), \mathrm{AV}-22$, yields mixed tetrahedral-octahedral frameworks, $\mathrm{K}_{3}\left[\mathrm{MSi}_{3} \mathrm{O}_{9}\right]$ or AV-23 materials (Figure 1a), which were characterized by powder and single-crystal X-ray diffraction. Because it was only possible to refine a structure for Tb-AV-23 (Y-AV-23 was confirmed by single-crystal XRD to be isostructural), here we shall focus on this material.

The structure of Tb-AV-23 contains a single crystallographically independent $\mathrm{Tb}^{3+}$ metal center coordinated to six $\left\{\mathrm{SiO}_{4}\right\}$ 

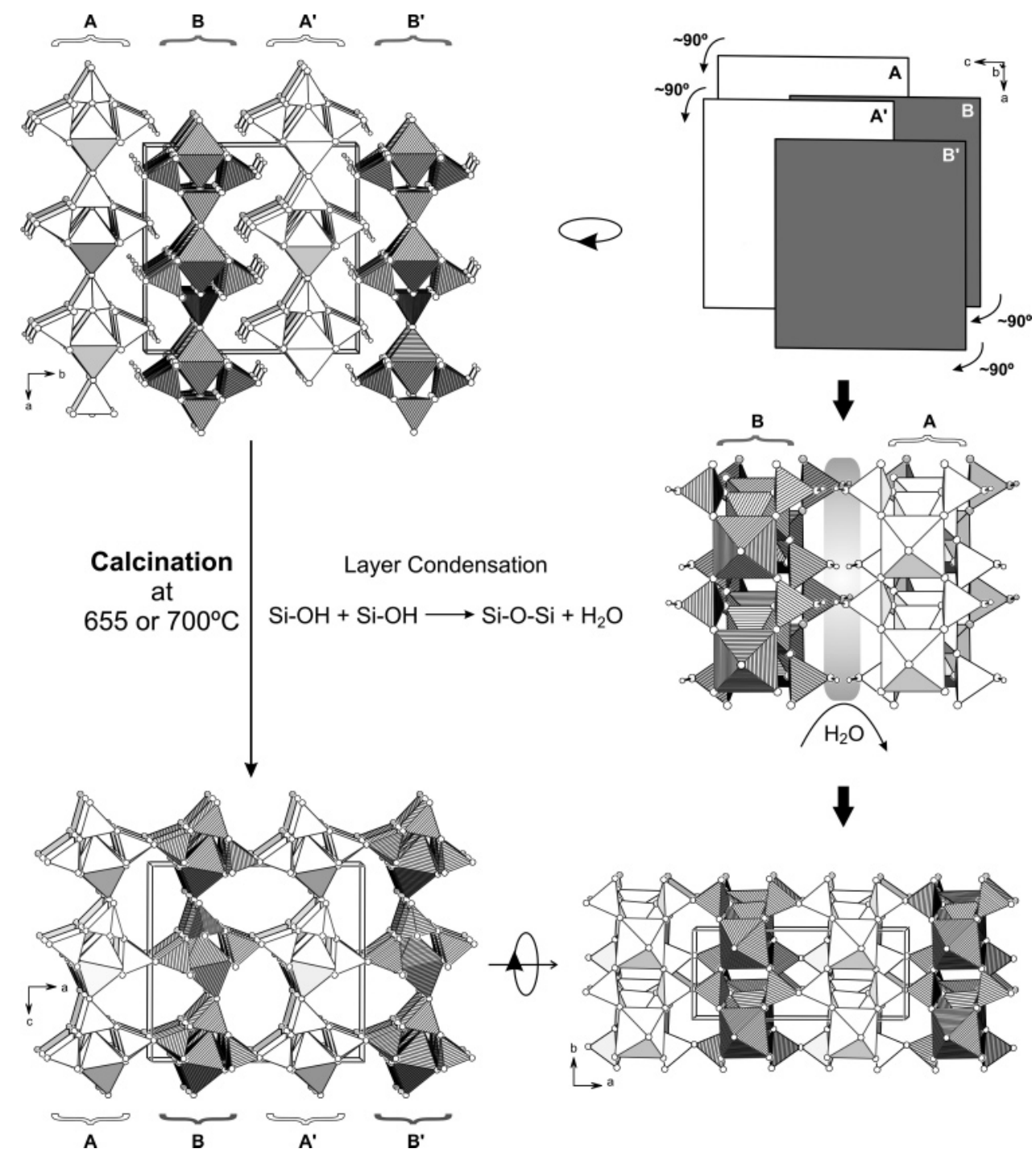

Figure 3. Schematic representation of the condensation $\left(\mathrm{SiOH}+\mathrm{SiOH} \rightarrow \mathrm{SiOSi}+\mathrm{H}_{2} \mathrm{O}\right)$ of adjacent anionic layers of $\mathrm{AV}-22$, yielding the framework of AV-23.

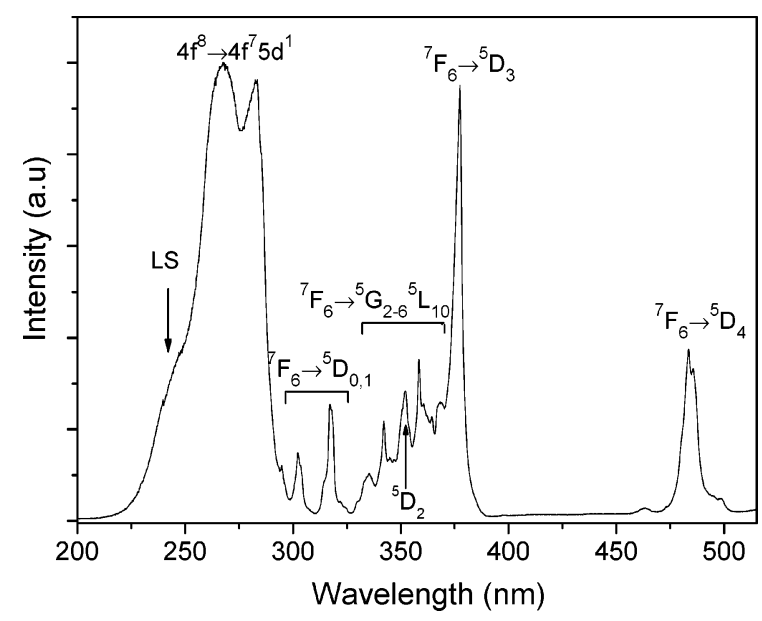

Figure 4. Excitation spectrum of Tb-AV-23, monitored at the ${ }^{7} \mathrm{~F}_{5}$ manifold (542 nm).

tetrahedra in a distorted octahedral geometry $\left(\left\{\mathrm{TbO}_{6}\right\}\right.$, Figure $1 b)$ : the $\mathrm{Tb}-\mathrm{O}$ bond distances are in the range 2.263(14)2.346(14) $\AA$, while the cis and trans octahedral angles are 82.5$(6)-96.3(6)^{\circ}$ and $171.6(6)-175.6(6)^{\circ}$, respectively (Table 2 ). Individual $\left\{\mathrm{TbO}_{6}\right\}$ octahedra are isolated from each other by wollastonite-type siliceous chains, $\left(\mathrm{Si}_{6} \mathrm{O}_{17}\right)_{n}{ }^{10 n-}$, running parallel

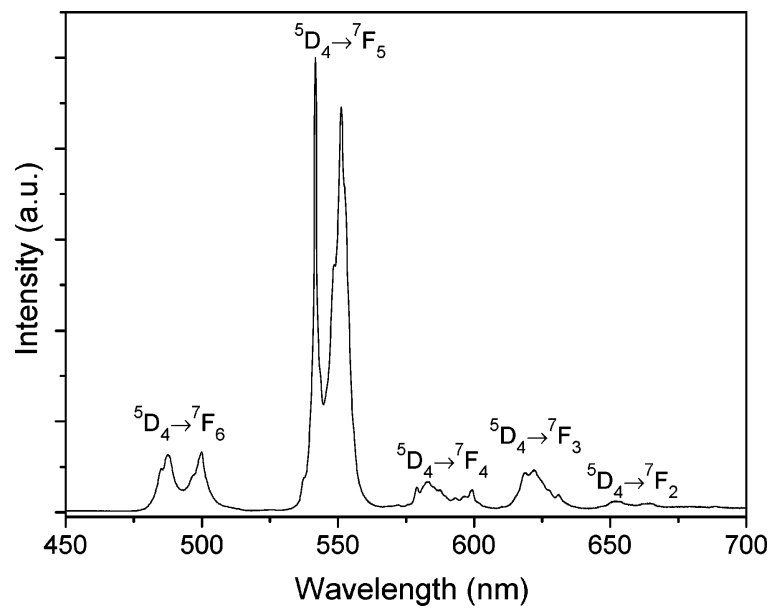

Figure 5. Emission spectrum of Tb-AV-23, excited at the ${ }^{5} \mathrm{D}_{3}$ manifold (377 nm).

to the $a$ axis of the unit cell (Figure 1c). The shortest $\mathrm{Tb}^{\circ} \cdots \mathrm{Tb}^{\mathrm{i}}$ internuclear distance is 5.909(1) $\AA$ [symmetry code (i) $x, 1+$ $y, z]$, a value which is retained from the parent AV-22 distance for the individual anionic $\left[\mathrm{TbSi}_{3} \mathrm{O}_{8}(\mathrm{OH})_{2}\right]_{n}{ }^{3 n-}$ layers. When these layers fuse upon calcination (see the discussion below concerning the likely condensation mechanism), the individual 


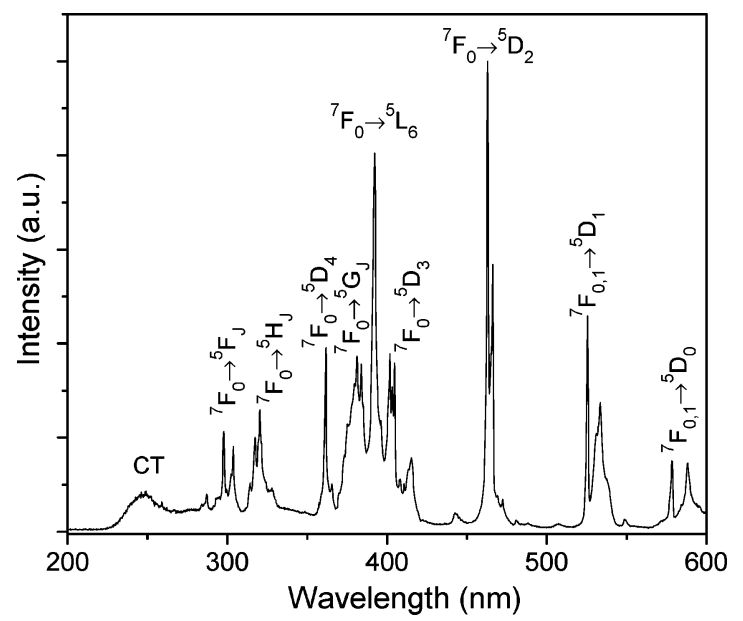

Figure 6. Excitation spectrum of Eu-AV-23, monitored at the ${ }^{7} \mathrm{~F}_{2}$ manifold $(610 \mathrm{~nm})$.

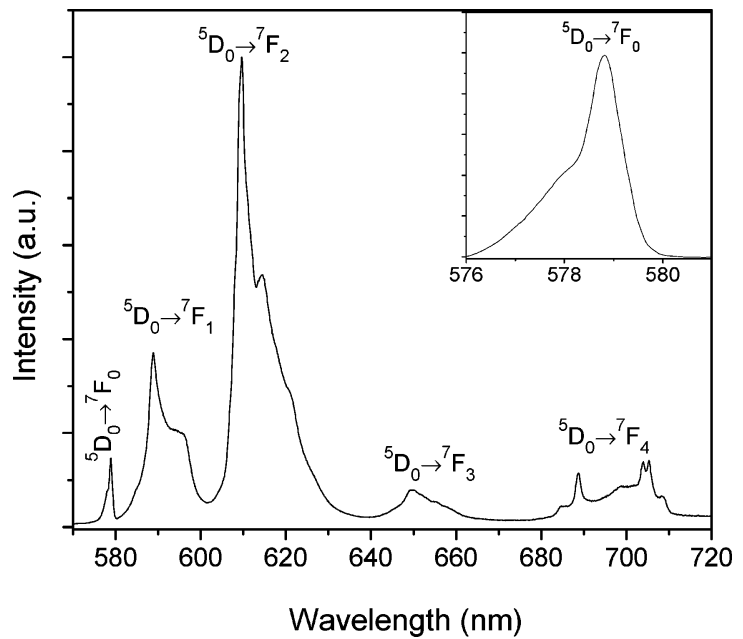

Figure 7. Emission spectrum of Eu-AV-23, excited at the ${ }^{5} \mathrm{~L}_{6}$ manifold (392 nm).

triple siliceous units are joined together, leading to the formation of wollastonite-type silica chains and imposing a new Tb... $\mathrm{Tb}^{\mathrm{iii}}$ separation of 7.206(1) $\AA$ [symmetry code (iii) $-x, y, z$ ].

The anionic $\left[\mathrm{TbSi}_{3} \mathrm{O}_{9}\right]_{n}{ }^{3 n-}$ framework is characterized by a three-dimensional channel system, filled with highly disordered $\mathrm{K}^{+}$cations, with the main tunnels running parallel to the [100] and [010] directions. The former are reminiscent of the distorted seven-membered pores of the anionic $\left[\mathrm{TbSi}_{3} \mathrm{O}_{8}(\mathrm{OH})_{2}\right]_{n}{ }^{3 n-}(\mathrm{Tb}-$ $\mathrm{AV}-22$ ) layers which, upon layer condensation, align with the $a$ axis, forming channels. The latter, more regular channels are formed by eight-membered elliptical rings with a cross-section of ca. $2.0 \times 4.0 \AA$ (Figure 1a). The adjacent channels along [100] and [001] are mutually rotated by $90^{\circ}$, leading to a typical basketweave-type distribution (Figure 1a).

The ${ }^{29} \mathrm{Si}$ MAS NMR spectrum of Y-AV-23 (Figure 2) displays three resonances at $-82.1,-83.1$, and $-87.7 \mathrm{ppm}$ in a 1:1:1 intensity ratio, in accord with the XRD crystal structure, which calls for the presence of three $\mathrm{Si}$ local environments with 1:1:1 populations. All Si sites have as second-nearest neighbors two Si and two Y atoms. Assuming the well-known correlation between the ${ }^{29} \mathrm{Si}$ isotropic chemical shift and the average $\mathrm{Si}-$ $\mathrm{O}-\mathrm{Si}$ bond angle holds, ${ }^{17}$ the resonances are tentatively assigned as follows: $-87.7 \mathrm{ppm}$ to $\mathrm{Si}(3)$ (average bond angle $149.7^{\circ}$ ), $-83.1 \mathrm{ppm}$ to $\operatorname{Si}(1)\left(141.0^{\circ}\right)$, and $-82.1 \mathrm{ppm}$ to $\operatorname{Si}(2)\left(135.5^{\circ}\right)$. Indeed, if one uses the simple correlation $\delta=-0.555 \alpha-7.462$, valid for $\mathrm{Q}^{4}(4 \mathrm{Al})$ zeolites, the calculated isotropic chemical shifts
TABLE 3: ${ }^{5} \mathrm{D}_{4}$ Lifetimes of Tb-AV-22 and Tb-AV-23 Measured at 300 and $10 \mathrm{~K}$ (Excitation Wavelength $377 \mathrm{~nm}$ )

\begin{tabular}{lcccc}
\hline & Tb-AV-22 & & \multicolumn{2}{c}{ Tb-AV-23 } \\
\cline { 2 - 3 } \cline { 4 - 5 } & $300 \mathrm{~K}$ & & $300 \mathrm{~K}$ & $10 \mathrm{~K}$ \\
\hline$\lambda_{\text {emis }}(\mathrm{nm})$ & 540.5 & & 541.7 & 541.7 \\
$\tau_{\mathrm{I}}(\mathrm{ms})$ & $4.45 \pm 0.02$ & & $4.02 \pm 0.02$ & $4.78 \pm 0.02$ \\
$\tau_{\text {II }}(\mathrm{ms})$ & & & $1.17 \pm 0.02$ & $2.88 \pm 0.02$
\end{tabular}

are, respectively, $-90.5,-85.7$, and $-82.7 \mathrm{ppm}$, in good agreement with our experimental results, considering the significant differences in the Si coordination spheres of AV-23 and zeolites.

Transformation of $\mathbf{A V - 2 2}$ to $\mathbf{A V - 2 3}$. We now try to rationalize the transformation of layered $\mathrm{AV}-22$ into small-pore $A V-23$. The former are built up of perforated anionic $\left[\mathrm{MSi}_{3} \mathrm{O}_{8}(\mathrm{OH})_{2}\right]_{n}{ }^{3 n-}$ layers in the ac plane, which pack along the [010] direction in an $[\mathrm{ABAB} . .$.$] fashion (Figure 3, top left).$ The three-dimensional anionic $\left[\mathrm{MSi}_{3} \mathrm{O}_{9}\right]_{n}{ }^{3 n-}(\mathrm{AV}-23)$ framework could, in principle, be generated by rotating half of the AV-22 layers by $180^{\circ}$, all in the same direction, thus removing the inversion symmetry relating adjacent layers. This process seems very unlikely. Alternatively, all AV-22 layers may rotate only by $90^{\circ}$ (A- and B-type layers rotating in opposite directions, Figure 3, top right), bringing closer the $\mathrm{SiOH}$ groups from adjacent layers. Condensation at high temperatures, with the corresponding release of one water molecule per formed $\mathrm{Si}-$ $\mathrm{O}-\mathrm{Si}$ bridge, yields the anionic $\left[\mathrm{MSi}_{3} \mathrm{O}_{9}\right]_{n}{ }^{3 n-}(\mathrm{AV}-23)$ framework. This condensation also produces a linear chain of cornersharing silicate tetrahedra (Figure 1c), making the final material an inosilicate of the pyroxenoid family (the wollastonite-type chain exhibits a repeating unit with more than two tetrahedral units). ${ }^{18}$ The condensation will only take place in an ordered way if the rotation of the layers is exactly $90^{\circ}$. However, at the relatively high temperature the materials are prepared, the kinetics of layer condensation is probably fast, and the mutual rotation of the layers may not always be complete $\left(<90^{\circ}\right)$. As a result, defect regions may form in the crystal, explaining the high mosaicity of the AV-23 crystals studied.

In summary, the AV-22 dehydration causes the disordered condensation of adjacent two-dimensional $\left[\mathrm{MSi}_{3} \mathrm{O}_{8}(\mathrm{OH})_{2}\right]_{n}{ }^{3 n-}$ nets, yielding AV-23, a material characterized by multiple crystal lattices. Thus, the AV-23 crystal structure described above is only a spatial average of all microdomains, explaining the high $R$ factors obtained (Table 1) and problems encountered while refining the model. This issue will be further addressed in Photoluminescence Studies.

Photoluminescence Studies. Figure 4 shows the excitation spectrum of Tb-AV-23, monitored at the ${ }^{5} \mathrm{D}_{4} \rightarrow{ }^{7} \mathrm{~F}_{5}$ transition of $\mathrm{Tb}^{3+}(542 \mathrm{~nm})$. The sharp lines between 300 and $500 \mathrm{~nm}$ are assigned to the intraconfigurational $4 \mathrm{f}^{8}$ transitions of $\mathrm{Tb}^{3+}$ between the ${ }^{7} \mathrm{~F}_{6}$ ground state and the ${ }^{5} \mathrm{D}_{4-0},{ }^{5} \mathrm{~L}_{10}$, and ${ }^{5} \mathrm{G}_{6-3}$ excited levels. The broad bands between 250 and $300 \mathrm{~nm}$ are ascribed to the spin-forbidden (high-spin, HS) interconfigurational $4 \mathrm{f}^{8} \rightarrow 4 \mathrm{f}^{7} 5 \mathrm{~d}^{1}$ (fd) transition of $\mathrm{Tb}^{3+} .19,20$ These $\mathrm{fd}$ bands may be observed for (heavy) $\mathrm{Ln}^{3+}$ ions with more than seven 4f electrons, at an energy lower than the energy of the spinallowed (low-spin, LS) fd transitions. The shoulder at ca. 240 $\mathrm{nm}$ is assigned to the LS interconfigurational fd transition of $\mathrm{Tb}^{3+}$.

The emission lines of Tb-AV-23 (Figure 5) are assigned to the ${ }^{5} \mathrm{D}_{4} \rightarrow{ }^{7} \mathrm{~F}_{2-6}$ transitions of $\mathrm{Tb}^{3+}$. Luminescence from the higher (e.g., ${ }^{5} \mathrm{D}_{3}$ ) excited states is not detected, indicating a very efficient nonradiative relaxation to the ${ }^{5} \mathrm{D}_{4}$ level. The deactivation of excited states by cross-relaxation between adjacent 
TABLE 4: ${ }^{5} \mathrm{D}_{0}$ Lifetimes of Eu-AV-22 and Eu-AV-23 Measured at 300 and $10 \mathrm{~K}$ (Excitation Wavelength $393 \mathrm{~nm}$ )

\begin{tabular}{|c|c|c|c|c|c|c|}
\hline & \multicolumn{2}{|c|}{ Eu-AV-22 } & \multicolumn{4}{|c|}{ Eu-AV-23 } \\
\hline & $300 \mathrm{~K}$ & $10 \mathrm{~K}$ & $300 \mathrm{~K}$ & & $10 \mathrm{~K}$ & \\
\hline$\lambda_{\text {emis }}(\mathrm{nm})$ & 609.5 & 609.5 & 609.5 & 615 & 609.5 & 615 \\
\hline$\tau_{\mathrm{I}}(\mathrm{ms})$ & $2.02 \pm 0.02$ & $2.49 \pm 0.02$ & $2.13 \pm 0.02$ & $2.13 \pm 0.03$ & $3.32 \pm 0.02$ & $3.27 \pm 0.03$ \\
\hline$\tau_{\mathrm{II}}(\mathrm{ms})$ & $0.58 \pm 0.02$ & $0.64 \pm 0.02$ & $1.25 \pm 0.03$ & $1.25 \pm 0.02$ & $1.40 \pm 0.01$ & $1.43 \pm 0.02$ \\
\hline$\tau_{\mathrm{III}}(\mathrm{ms})$ & & & & $0.33 \pm 0.01$ & & $0.40 \pm 0.01$ \\
\hline
\end{tabular}

TABLE 5: Room-Temperature Radiance for the Standard Green $\mathrm{Gd}_{2} \mathrm{O}_{2} \mathrm{~S}$ :Tb and $\operatorname{Red} \mathrm{Y}_{2} \mathrm{O}_{2}$ :Eu Phosphors, Tb- and Eu-AV-22, and Tb- and Eu-AV-23 Measured at Different Excitation Wavelengths $(\lambda)$

\begin{tabular}{lcccccc}
\hline & $\mathrm{Gd}_{2} \mathrm{O}_{2} \mathrm{~S}: \mathrm{Tb}$ & $\mathrm{Tb}-\mathrm{AV}-22$ & $\mathrm{~Tb}-\mathrm{AV}-23$ & $\mathrm{Y}_{2} \mathrm{O}_{2} \mathrm{~S}: \mathrm{Eu}$ & $\mathrm{Eu}-\mathrm{AV}-22$ & $\mathrm{Eu}-\mathrm{AV}-23$ \\
\hline$\lambda(\mathrm{nm})$ & 270 & 270 & 270 & 264 & 393 & 393 \\
radiance $\left(\mu \mathrm{W} / \mathrm{cm}^{2}\right)$ & 0.924 & 0.351 & 0.193 & 0.299 & 0.052 & 0.028
\end{tabular}

centers (concentration quenching) may also explain the absence of emission from high-energy states (e.g., $\left.{ }^{5} \mathrm{D}_{3}\right)$. The same emission is obtained with excitation at the maximum of the HS fd band. The presence of more than one local $\mathrm{Tb}^{3+}$ environment is detected in the ${ }^{5} \mathrm{D}_{4}$ decay curves (excited at 377 or $283 \mathrm{~nm}$ and detected at the ${ }^{5} \mathrm{D}_{4} \rightarrow{ }^{7} \mathrm{~F}_{5}$ transition). These curves (not shown) are well fitted by a biexponential function, yielding the two lifetimes depicted in Table 3 . We have previously shown that as-prepared $\mathrm{Tb}-\mathrm{AV}-22$ displays only one local $\mathrm{Tb}^{3+}$ site with a lifetime of $4.45 \mathrm{~ms},{ }^{5}$ similar to the Tb-AV-23 $\tau_{1}$ lifetime, $4.02 \mathrm{~ms}$. The crystal structures of AV-22 and AV-23 materials call for the presence of a single independent $\mathrm{Ln}^{3+}$ environment. As discussed above, the AV-23 crystals exhibit considerable internal disorder, indicated by the overall poor diffraction and high mosaicity. This suggests that the thermal transformation of AV-22 into AV-23 may generate defect crystal regions. Moreover, TGA analysis of AV-23 samples left in air for a few days reveals weight losses equivalent to ca. 0.5 water molecule, presumably associated with these defect regions. If so, the two lifetimes measured for AV-23 may be ascribed to $\mathrm{Ln}^{3+}$ centers in regular framework positions and in defect regions. The facts that (i) one of the lifetimes is significantly shorter $(1.17 \mathrm{~ms})$ than the other $(4.02 \mathrm{~ms})$ and (ii) $\tau_{\mathrm{I}}$ and $\tau_{\mathrm{II}}$ decrease, respectively $15 \%$ and $60 \%$ from $10 \mathrm{~K}$ to room temperature, support this hypothesis because in the defect regions $\mathrm{Ln}^{3+}$ ions are probably associated with water molecules. ${ }^{21}$

The excitation spectrum of Eu-AV-23 monitored at the ${ }^{5} \mathrm{D}_{0}$ $\rightarrow{ }^{7} \mathrm{~F}_{2}$ transition at $610 \mathrm{~nm}$ (Figure 6) displays a series of sharp lines assigned to the ${ }^{7} \mathrm{~F}_{0-1} \rightarrow{ }^{5} \mathrm{D}_{4-0},{ }^{5} \mathrm{~L}_{6},{ }^{5} \mathrm{G}_{2-6},{ }^{5} \mathrm{H}_{3-7}$, and ${ }^{5} \mathrm{~F}_{1-5}$ intra- $4 \mathrm{f}^{6}$ transitions of $\mathrm{Eu}^{3+}$. The broad band at $250 \mathrm{~nm}$ is assigned to a $\mathrm{Eu} \rightarrow \mathrm{O}$ charge-transfer transition.

The emission spectrum of Eu-AV-23 (excited at $392 \mathrm{~nm}$ ) is shown in Figure 7. The sharp emission lines are assigned to transitions between the first excited nondegenerate ${ }^{5} \mathrm{D}_{0}$ state and the ${ }^{7} \mathrm{~F}_{0-4}$ levels of the fundamental $\mathrm{Eu}^{3+}$ septet. Except for the ${ }^{5} \mathrm{D}_{0} \rightarrow{ }^{7} \mathrm{~F}_{1}$ lines, which have a predominant magnetic-dipole character, the observed transitions are mainly of electric-dipole nature. The ${ }^{5} \mathrm{D}_{0} \rightarrow{ }^{7} \mathrm{~F}_{1}$ magnetic transition is weaker than the ${ }^{5} \mathrm{D}_{0} \rightarrow{ }^{7} \mathrm{~F}_{2}$ forced electric-dipole one. The two ${ }^{5} \mathrm{D}_{0} \rightarrow{ }^{7} \mathrm{~F}_{0}$ lines reveal the presence of, at least, two distinct $\mathrm{Eu}^{3+}$ environments (inset in Figure 7). $\mathrm{Eu}^{3+}$ luminescence from higher excited states, such as ${ }^{5} \mathrm{D}_{1}$, is not detected, indicating a very efficient nonradiative relaxation to the ${ }^{5} \mathrm{D}_{0}$ level. As mentioned before, the deactivation of excited states by cross-relaxation between adjacent centers may also explain the absence of the ${ }^{5} \mathrm{D}_{1}$ emission. This is confirmed by the similarity of the steadystate and time-resolved spectra (not shown) in the ${ }^{5} \mathrm{D}_{0} \rightarrow{ }^{7} \mathrm{~F}_{1}$ region $\left({ }^{5} \mathrm{D}_{1} \rightarrow{ }^{7} \mathrm{~F}_{3}\right.$ lines are not observed).

These local environments were further investigated by recording the decay curves on the ${ }^{7} \mathrm{~F}_{0-2}$ levels as a function of the excitation wavelength (392 or $463 \mathrm{~nm}$ ). The results are well fitted by (i) biexponential functions when monitoring at the maximum of the ${ }^{5} \mathrm{D}_{0} \rightarrow{ }^{7} \mathrm{~F}_{1,2}$ transitions and (ii) threeexponential functions when monitoring both at the maximum of the ${ }^{5} \mathrm{D}_{0} \rightarrow{ }^{7} \mathrm{~F}_{0}$ transition and at the low-energy side of the ${ }^{5} \mathrm{D}_{0} \rightarrow{ }^{7} \mathrm{~F}_{2}$ transition. The lifetimes of AV-22 and AV-23 are gathered in Table 4.

Detailed photoluminescence studies of AV-22 have shown that the $\mathrm{Eu}^{3+}$ ions may be present in regular crystallographic positions in the layers (site I with the larger lifetime $\tau_{\mathrm{I}}$ ) and replacing the $\mathrm{K}^{+}$ions residing in the pores of the layers and/or in the interlayer space (site II with smaller lifetime $\tau_{\mathrm{II}}$ ). The transformation of the layered AV-22 material to small-pore AV23 generates three $\mathrm{Eu}^{3+}$ local environments. The lifetime of one of these sites is similar to that of site I in AV-22, respectively 2.13 and $2.02 \mathrm{~ms}$, and, thus, is attributed to $\mathrm{Eu}^{3+}$ ions in the framework, which is, essentially, built up of fused AV-22 layers. The smallest AV-23 lifetime $(0.33 \mathrm{~ms})$ is ascribed to $\mathrm{Eu}^{3+}$ ions in defect regions associated with water molecules, and therefore, $\mathrm{AV}-23$ site II must be assigned to $\mathrm{Eu}^{3+}$ ions replacing $\mathrm{K}^{+}$ions in the micropores. The comparison of the emission spectra of Eu-AV-22 $2^{5}$ and Eu-AV-23 (Figure 7) in the ${ }^{5} \mathrm{D}_{0} \rightarrow{ }^{7} \mathrm{~F}_{2}$ region supports this assignment. Indeed, the two spectra are quite similar in the high-energy region of the ${ }^{5} \mathrm{D}_{0} \rightarrow{ }^{7} \mathrm{~F}_{2}$ transition. The ${ }^{5} \mathrm{D}_{0}$ decay curves monitored at this energy are well fitted by two exponential functions, yielding the two lifetimes depicted in Table 4. The lifetime of site II is larger for Eu-AV-23, in accord with the absence of $\mathrm{OH}$ groups due to the calcination process. The $\mathrm{Eu}^{3+}$ site corresponding to the regular crystallographic position shows the smallest fwhm $\left(21.5 \mathrm{~cm}^{-1}\right)$. The site ascribed to $\mathrm{Eu}^{3+}$ substituting for $\mathrm{K}^{+}$exhibits larger local disorder, witnessed by the larger fwhm $\left(26.5 \mathrm{~cm}^{-1}\right)$, while the third site ascribed to $\mathrm{Eu}^{3+}$ in defect crystal regions displays the largest fwhm $\left(44.0 \mathrm{~cm}^{-1}\right)$.

The radiances of Eu-AV-22 and Tb- and Eu-AV-23 samples and standard $\mathrm{Gd}_{2} \mathrm{O}_{2} \mathrm{~S}$ : Tb, green, and $\mathrm{Y}_{2} \mathrm{O}_{2}$ : Eu, red, phosphors were measured and compared for different excitation wavelengths (Table 5). The Tb-AV-23 radiance at $270 \mathrm{~nm}$ is ca. $55 \%$ smaller than that of Tb-AV-22, which, in turn, is ca. $60 \%$ smaller than the radiance of $\mathrm{Gd}_{2} \mathrm{O}_{2} \mathrm{~S}$ : Tb. The Eu-AV-23 radiance at 393 $\mathrm{nm}$ is ca. $54 \%$ smaller than that of Eu-AV-22, which, itself, is 1 order of magnitude smaller than the $\mathrm{Y}_{2} \mathrm{O}_{2}$ :Eu radiance (264 $\mathrm{nm}$ excitation). The lower radiance of $\mathrm{AV}-23$ relative to $\mathrm{AV}$ 22 is due to more effective nonradiative channels caused by the presence in the former of defect crystal regions.

FT-Raman spectra were recorded to quantitatively study the $\mathrm{PL}$ intensity as a function of the $\mathrm{Er}^{3+}$ content in the Y/Er-AV23 system $\mathrm{K}_{3}\left(\mathrm{Y}_{1-a} \mathrm{Er}_{a} \mathrm{Si}_{3} \mathrm{O}_{9}\right), a=0.005-1$ (Figure 8). As expected, the vibronic transitions appear in the Raman shift range $50-1200 \mathrm{~cm}^{-1}$ (not shown), while the intra- $4 \mathrm{f}^{11}$ electronic transitions are detected at $3500-2500 \mathrm{~cm}^{-1}$. The emission lines are assigned to the intra- $4 \mathrm{f}^{11}$ transitions between the ${ }^{4} \mathrm{I}_{13 / 2}$ and 


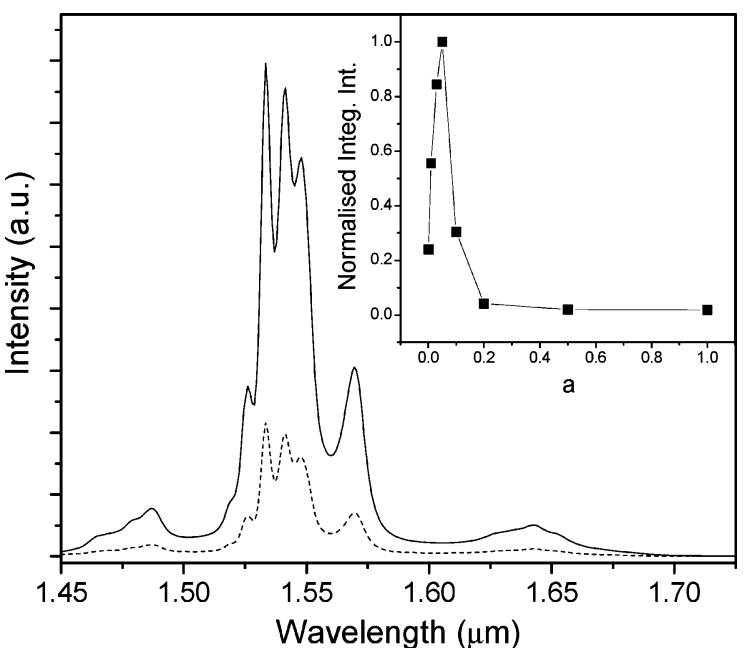

Figure 8. FT-Raman spectra of $\mathrm{K}_{3}\left(\mathrm{Y}_{1-a} \mathrm{Er}_{a} \mathrm{Si}_{3} \mathrm{O}_{9}\right), a=0.05$ (solid line) and $a=0.005$ (dashed line). The inset depicts the normalized integrated intensity of the $1.54 \mu \mathrm{m}$ photoluminescence as a function of the $\mathrm{Er}^{3+}$ content for the samples with $a$ in the range 0.005-1.

TABLE 6: ${ }^{4} \mathbf{I}_{13 / 2}$ Lifetimes of $\mathrm{K}_{3}\left(\mathrm{Y}_{1-a} \mathrm{Er}_{a} \mathrm{Si}_{3} \mathrm{O}_{9}\right)(a=$ 0.01-0.20) Excited at $376 \mathrm{~nm}$ and Room Temperature

\begin{tabular}{lcccc}
\hline & $a=0.01$ & $a=0.05$ & $a=0.10$ & $a=0.20$ \\
\hline$\tau_{\mathrm{I}}(\mathrm{ms})$ & $7.71 \pm 0.20$ & $3.90 \pm 0.03$ & $1.99 \pm 0.04$ & $0.57 \pm 0.01$ \\
$\tau_{\mathrm{II}}(\mathrm{ms})$ & $1.11 \pm 0.06$ & $0.81 \pm 0.03$ & $0.42 \pm 0.03$ & $0.15 \pm 0.01$
\end{tabular}

${ }^{4} \mathrm{I}_{15 / 2}$ levels of the ground multiplet of $\mathrm{Er}^{3+}$. Provided the intensities of the vibrational spectra of the different samples in the series are similar, the variation of the PL intensity as a function of the $\mathrm{Er}^{3+}$ content may be estimated directly from the intensity of the strongest electronic line $(1.54 \mu \mathrm{m})$ in the $3500-2500 \mathrm{~cm}^{-1}$ region (inset in Figure 8). In Y/Er-AV-23 the ${ }^{4} \mathrm{I}_{13 / 2} \rightarrow{ }^{4} \mathrm{I}_{15 / 2}$ PL integrated area increases with increasing $\mathrm{Er}^{3+}$ content, from 0.005 to 0.05 , and then decreases, reaching 0.04 for $a=0.2$ and 0.02 for $a=0.5$. This suggests that PL first increases due to the increase in the number of optically active centers, but after the maximum, at ca. $a=0.05$, the PL is strongly quenched by $\mathrm{Er}^{3+}-\mathrm{Er}^{3+}$ interactions. These interactions were further investigated by room-temperature ${ }^{4} \mathrm{I}_{13 / 2}$ decay curves (excitation at $376 \mathrm{~nm}$ ), which are well fitted by biexponential functions, indicating the presence of two $\mathrm{Er}^{3+}$ sites (Table 6). Increasing the $\mathrm{Er}^{3+}$ content leads to a decrease of the lifetimes, which is more significant for the larger lifetime, attributed to $\mathrm{Er}^{3+}$ ions in regular crystallographic positions in the layers. Quenching is observed for $a=0.05$, due to $\mathrm{Er}^{3+}-$ $\mathrm{Er}^{3+}$ interactions, suggesting that the maximum efficiency is reached at low $\mathrm{Er}^{3+}$ concentrations.

\section{Conclusions}

The structural characterization of small-pore $\mathrm{K}_{3} \mathrm{LnSi}_{3} \mathrm{O}_{9}$, $\mathrm{Ln}$ $=\mathrm{Y}, \mathrm{Eu}, \mathrm{Tb}$, and Er, named AV-23, has been reported. The dehydratation process of layered lanthanide silicates $\mathrm{K}_{3}\left[\mathrm{LnSi}_{3} \mathrm{O}_{8^{-}}\right.$ $\left.(\mathrm{OH})_{2}\right], \mathrm{Ln}=\mathrm{Y}, \mathrm{Eu}, \mathrm{Tb}$, and $\mathrm{Er}, \mathrm{AV}-22$, into AV-23 materials has been rationalized. The crystal structure of the latter materials calls for the presence of a single independent $\mathrm{Ln}^{3+}$ environment. Despite this, detailed PL studies showed the presence of two or three $\mathrm{Ln}^{3+}$ sites, which may be ascribed to metal centers in regular framework positions, defect regions, and micropores, replacing $\mathrm{K}^{+}$. The lifetimes of the $\mathrm{Ln}^{3+}$ species in the layers of $\mathrm{AV}-22$ and in the framework of AV-23 are only slightly different $(4.45$ and $4.02 \mathrm{~ms}$, and 2.02 and $2.13 \mathrm{~ms}$ for, respectively, $\mathrm{Tb}$ - and Eu-containing materials). The maximum emission efficiency of $\mathrm{K}_{3}\left(\mathrm{Y}_{1-a} \mathrm{Er}_{a} \mathrm{Si}_{3} \mathrm{O}_{9}\right), a=0.005-1$, samples is observed for $0.01 \leq a \leq 0.05$, indicating that $\mathrm{Er}^{3+}-\mathrm{Er}^{3+}$ interactions quench the PL, decreasing the ${ }^{4} \mathrm{I}_{13 / 2}$ lifetime as the $\mathrm{Er}^{3+}$ content increases. The PL properties are, therefore, adjusted by changing the dimensionality of the lanthanide silicates.

Acknowledgment. We thank FCT, FEDER, POCTI, and NoE FAME. M.H.K. thanks FCT for a Ph.D. grant (SFRH/ $\mathrm{BD} / 12323 / 2003)$.

\section{References and Notes}

(1) Ananias, D.; Ferreira, A.; Rocha, J.; Ferreira, P.; Rainho, J. P.; Morais, C.; Carlos, L. D. J. Am. Chem. Soc. 2001, 123, 5735.

(2) Ferreira, A.; Ananias, D.; Carlos, L. D.; Morais, C. M.; Rocha, J. J. Am. Chem. Soc. 2003, 125, 14573.

(3) Ananias, D.; Almeida Paz, F. A.; Carlos, L. D.; Geraldes, C. F. G. C.; Rocha, J. Angew. Chem., Int. Ed. 2006, 45, 7938.

(4) Wang, G.; Li, J.;Yu, J.; Chen, P.; Pan, Q.; Song, H.; Xu, R. Chem. Mater. 2006, 18, 5637.

(5) Ananias, D.; Kostova, M.; Almeida Paz, F. A. A.; Ferreira, A.; Carlos, L. D.; Klinowski, J.; Rocha, J. J. Am. Chem. Soc. 2004, 126, 10410 7,199

(6) Rocha, J.; Carlos, L. D. Curr. Opin. Solid State Mater. Sci. 2003,

(7) Pan, L.; Huang, X.; Li, J.; Wu, Y.; Zheng, N. Angew. Chem., Int. Ed. 2000, 39, 527.

(8) Huang, Z.; Strobele, M.; Zhang, K. L.; Meyer, H. J.; You, X. Z.; $\mathrm{Yu}, \mathrm{Z}$. Inorg. Chem. Commun. 2002, 5, 230.

(9) Serpaggi, F.; Férey, G. Inorg. Chem. 1999, 38, 4741.

(10) Ponomarev, V. I.; Filipenko, O. S.; Atovmyan, L. O. Kristallografiya 1988, 33, 98.

(11) Kottke, T.; Stalke, D. J. Appl. Crystallogr. 1993, 26, 615.

(12) SMART, Bruker Molecular Analysis Research Tool, version 5.054; Bruker AXS: Madison, WI, 1997-98.

(13) SAINTPlus, Data Reduction and Correction Program, version 6.01; Bruker AXS: Madison, WI, 1997-98.

(14) Sheldrick, G. M. SADABS, Bruker/Siemens Area Detector Absorption Correction Program, version 2.01; Bruker AXS: Madison, WI, 1998

(15) Sheldrick, G. M. SHELXS-97, Program for Crystal Structure Solution; University of Göttingen: Göttingen, Germany, 1997.

(16) Sheldrick, G. M. SHELXL-97, Program for Crystal Structure Refinement; University of Göttingen: Göttingen, Germany, 1997.

(17) Engelhardt G.; Michel D. High-resolution solid-state NMR of silicates and zeolites; John Wiley \& Sons Ltd.: Chichester, U.K., 1987.

(18) Henry, M. Coord. Chem. Rev. 1998, 180, 1109.

(19) Laroche, M.; Doualan, J. L.; Girard, S.; Margerie, J.; Moncorgé, R. J. J. Opt. Soc. Am. B 2000, 17, 1291.

(20) van Pierterson, L.; Reid, M. F.; Burdick, G. W.; Meijerink, A. Phys. Rev. B 2002, 65, 045144 .

(21) Bünzli, J. C. G., Choppin, G. R., Eds. Lanthanide Probes in Life, Chemicle and Earth Science-Theory and Practice; Elsevier: Amsterdam, 1989; Chapter 7. 